\title{
Experimental review of oxygen content at mixing layer in cone calorimeter
}

\author{
Alain Alonso ${ }^{1}$, Eduardo Puente ${ }^{1}$, Pedro Lázaro ${ }^{1}$, David Lázaro ${ }^{1}$, Daniel Alvear ${ }^{1}$ \\ ${ }^{1}$ GIDAI, University of Cantabria, Avda. Los Castros, s/n, 39005 Santander. Spain
}

\begin{abstract}
This work aims to elucidate whether the hypothesis of zero-oxygen at the mixture layer when flame takes place is assumable for every kind of material. For that purpose, we investigated the oxygen concentration there by cone calorimeter tests. A modified holder was developed in order to collect oxygen in this mixture layer. In addition, thermogravimetric tests were carried out so as to relate the possible effects of the presence of oxygen in the atmosphere where the pyrolysis process takes place, since the cone calorimeter does not allow to control the oxygen level of the atmosphere during the experiment. The reaction rates and percent of residue in the cone calorimetric tests were measured and compared with the results from thermogravimetric tests. Six products were analysed which can be classified in three main groups: lignocellulosic, thermoplastic polymers and thermoset polymers. Cone calorimetric results showed that for some of the materials analysed (PET, Nylon and PUR foam) the oxygen level at mixture layer decreased until values close to zero. The comparison of reaction rates between cone calorimetric and thermogravimetric tests revealed the char layer created in cone calorimetric tests over the exposed face for brushed fir, Nylon and PET established an important heat barrier that modifies the thermal behaviour of these materials
\end{abstract}

\section{Keywords}

Cone calorimeter, thermal oxidation of char, oxygen concentration, carbon dioxide concentration, pyrolysis behaviour, thermogravimetric analysis.

\section{Nomenclature}

\begin{tabular}{|c|c|c|c|}
\hline$\dot{H}_{\text {flux }} \cdot \overrightarrow{c o n e}$ & $\begin{array}{l}\text { Incident flux from cone } \\
\text { calorimeter } / \mathrm{kW} \cdot \mathrm{m}^{-2}\end{array}$ & $\dot{\mathrm{m}}_{\text {peak }}$ & $\begin{array}{l}\text { Peak of the mass flow released by the sample } \\
\text { and measured by the cone in the exhaust } \\
\text { tube } / \mathrm{kg} \cdot \mathrm{s}^{-1}\end{array}$ \\
\hline$\overline{\mathrm{T}}$ & $\begin{array}{l}\text { Average temperature of the surface of } \\
\text { the sample during the test after the } \\
\text { ignition } /{ }^{\circ} \mathrm{C}\end{array}$ & $\dot{\mathrm{q}} \begin{array}{l}\text { peak } \\
\text { cone }\end{array}$ & $\begin{array}{l}\text { HRR peak during the test released by the sample in } \\
\text { cone test without gas sampling tubes } / \mathrm{kW} \cdot \mathrm{m}^{-2}\end{array}$ \\
\hline$\dot{\mathrm{m}}_{\mathrm{s}}$ & Sampling mass flow $/ \mathrm{kg} \cdot \mathrm{s}^{-1}$ & $\dot{\mathrm{q}}$ gas & $\begin{array}{l}\text { HRR peak during the test released by the sample in } \\
\text { cone test with gas sampling tubes } / \mathrm{kW} \cdot \mathrm{m}^{-2} /\end{array}$ \\
\hline$\dot{\mathrm{m}}_{\mathrm{avg}}$ & $\begin{array}{l}\text { Average mass flow released by the } \\
\text { sample and measured by the cone in } \\
\text { the exhaust tube } / \mathrm{kg} \cdot \mathrm{s}^{-1}\end{array}$ & & \\
\hline
\end{tabular}

\section{Introduction}

Oxygen concentration has a strong effect on fire behavior of materials, i.e. they decompose in different ways, and then, mass loss rate become faster [1]. The onset temperature of reaction also depends on the oxygen concentration, becoming smaller, in most of cases, whether thermal oxidation or decomposition is occurring respectively. Furthermore, oxygen diffusion into the material is determined by partial pressure of oxygen at the surface.

Thermal analysis techniques have been used for years [2] to evaluate experimental properties of materials, especially those related to thermal decomposition and oxidation parameters, such as, specific heat, conductivity and few reaction (kinetic) ones. These techniques provide useful tools to characterize the behavior of single materials in fires. Among them, thermogravimetry -TG- and differential scanning calorimetry -DSC [3] are the most common. Those techniques and bench scale calorimetric analysis, i.e. cone calorimeter [4] have been used to obtain a set of parameters (based on real properties) which tunes pyrolysis models appropriately. For example, by using optimization techniques to find unknown properties there are several works [5-9], which are applied jointly with simplified numerical models to evaluate the rate of mass loss against temperature with a degree of accuracy previously established for TG and cone calorimetric.

A typical TG test can be carried out at different levels of oxygen concentration, either reactive (frequently air) or inert (nitrogen usually). By the contrast, standard procedure in cone calorimetric and by far the most scientific data obtained from cone calorimeter were carried out in air atmosphere [10-13]. Whereas little work was dedicated to study different levels of 
oxygen concentration when the scheme of reaction of the material is characterized. Some researchers [14-19] argue that after material ignition, flame consumes all the oxygen evolving reactive interphase (zero oxygen hypotheses) and thus, material decomposes in non-oxidant conditions. Liu et al. [14] and Sacristán et al. [15] analyzed, under different levels of oxygen concentration, several polymers comparing char yields and residues in cone calorimeter and TG respectively and they reported a good relationship between char yield from cone and inert TG. In their guide, Kim and Dembsey [20] suggested that TG data obtained under inert atmospheres are more useful than data from oxidant atmospheres in order to understand pyrolysis behavior in fire conditions. However, Lyon [21] underlined this question and focused the matter over the significance of oxidation in char residues, since final mass of residue of charring materials from cone calorimeter fitted so well with final mass residue from TG experiments up to $900^{\circ} \mathrm{C}$. The result of that question is that most of the works consider pyrolysis of the condensed phase (pyrolysis zone) is essentially anaerobic and use quantitatively data from inert atmospheres so as to obtain the kinetic properties of reactions that material undergoes during pyrolysis, while data from reactive atmospheres have used only qualitatively, i.e. for describing the thermodynamics of each step that compounds the chemical mechanism of pyrolysis.

The previous statement could not be valid for every single material, and along this lines, some recent works [22,23] demonstrate the influence of the oxygen concentration in the cone calorimeter results by modifying it and developing the Controlled Atmosphere Pyrolysis Apparatus (CAPA).

In order to elucidate under which conditions and materials, the zero-oxygen hypothesis is valid, we analyzed three types of materials (lignocellulosic materials, thermoplastic and thermoset polymers). Moreover, in this work it is proposed a new method to measure the oxygen concentration in the mixture layer modifying the cone calorimetric sample holder.

\section{Materials}

Materials analysed in this work are listed in next Table 1.

Table 1. List of tested materials

\begin{tabular}{lllll}
\hline Type & Material & $\begin{array}{l}\text { Average } \\
\text { density } / \mathrm{kg} \mathrm{m}^{-3}\end{array}$ & Standard deviation & $\begin{array}{l}\text { * Latin name } \\
\text { Chemical formula }\end{array}$ \\
\hline Lignocellulosic & $\begin{array}{l}\text { Brushed fir } \\
\text { Corrugated cardboard }\end{array}$ & $\begin{array}{l}424.0 \\
571.5\end{array}$ & $\begin{array}{l}15.75 \\
20.17\end{array}$ & * Pseudotsuga menziesii \\
\hline $\begin{array}{l}\text { Thermoplastic } \\
\text { polymers }\end{array}$ & $\begin{array}{l}\text { PVC (Polyvinyl } \\
\text { chloride) wall panelling } \\
\text { Nylon 66 }\end{array}$ & 1567.8 & 30.99 & $\left(\mathrm{C}_{2} \mathrm{H}_{3} \mathrm{Cl}\right)_{\mathrm{n}}$ \\
\hline $\begin{array}{l}\text { Thermoset } \\
\text { polymers }\end{array}$ & $\begin{array}{l}\text { Polyurethane foam } \\
\text { PET (Polyethylene }\end{array}$ & 41.5 & 22.90 & $\left(\mathrm{C}_{12} \mathrm{H}_{22} \mathrm{~N}_{2} \mathrm{O}_{2}\right)_{\mathrm{n}}$ \\
\hline
\end{tabular}

All samples were previously conditioned in an environment of $50 \%$ relative humidity $( \pm 5 \%)$ and $23^{\circ} \mathrm{C}\left( \pm 3^{\circ} \mathrm{C}\right)$ until a stable specimen weight is reached [3-4]. Lignocellulosic materials did not have any surface finish and all materials had a homogenous cross section apart from the cardboard and the PVC wall panelling. The description of these heterogeneous cross section materials is shown in Fig. 1.

(a)

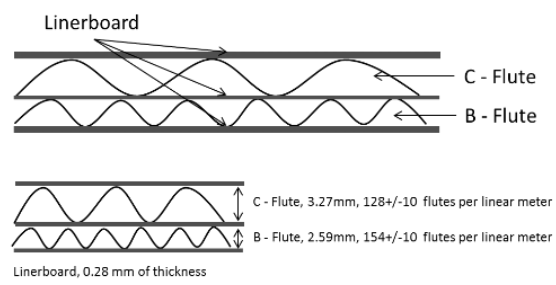

(b)

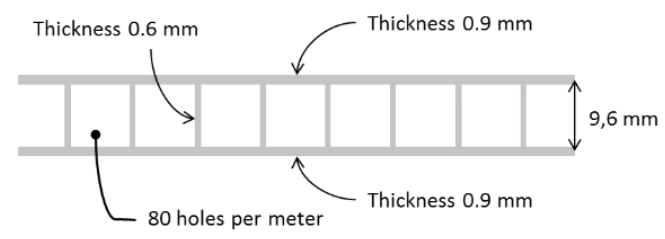

Fig. 1. a Schematic draw of double layer corrugated sample, b PVC wall panelling.

All cone specimens were slabs of $100 \times 100 \mathrm{~mm}$ in surface area and their average thickness and initial mass are presented in Table 2. 
Table 2. List of tested materials in cone calorimeter

\begin{tabular}{lll} 
Material & Thickness average/mm & Sample mass average/g \\
\hline Brushed fir & 11.9 & 48.8 \\
Corrugated cardboard & 6.6 & 7.9 \\
PVC wall panelling & 9.6 & 18.5 \\
Nylon 66 & 11.2 & 127.7 \\
Polyurethane foam & 34.2 & 15.2 \\
PET & 12.96 & 167.2 \\
\hline
\end{tabular}

Table 3 indicates the initial mass of the materials tested.

Table 3. List of tested materials in TG

\begin{tabular}{lll}
\hline Material & $\begin{array}{l}\text { Sample mass/mg } \\
\text { Air atmosphere test }\end{array}$ & $\begin{array}{l}\text { Sample mass/mg } \\
\mathrm{N}_{2} \text { atmosphere test }\end{array}$ \\
\hline Brushed fir & 9.903 & 11.253 \\
Corrugated cardboard & 18.923 & 5.733 \\
PVC wall panelling & 12.824 & 13.821 \\
Nylon 66 & 17.717 & 16.136 \\
Polyurethane foam & 2.630 & 3.066 \\
PET & 12.593 & 15.566 \\
\hline
\end{tabular}

\section{Experimental set-up}

Thermogravimetric test were carried out by the $S T A 449 \mathrm{~F} 3$. The material of crucible was $\mathrm{Al}_{2} \mathrm{O}_{3}$ and had an area of $6 \mathrm{~mm}$ of diameter. Every test was executed under two types of atmospheres, $\mathrm{N}_{2}$ and air, without lid and applying a heating rate of 10 ${ }^{\circ} \mathrm{C} \mathrm{min}{ }^{-1}$ from $25^{\circ} \mathrm{C}$ to $800{ }^{\circ} \mathrm{C}$. The purge flow for all tested samples was $260 \mathrm{ml} \mathrm{min}{ }^{-1}$. Table 3 indicates the initial mass of the materials tested.

In cone calorimetric test, according to the procedures of ASTM E 1354 04a [4], smoke measuring system is located in the tube of the exhaust system of the cone calorimetric and obviously that position of the gas sampler is not suitable to measure the oxygen concentration in the mixture layer since combustion effluents are highly dissolved in the surrounded air. In order to analyse the oxygen in that mixture layer, a modified holder was built (refer to Fig. 2). They consisted in two stainless steel sample tubes of $4.5 \mathrm{~mm}$ of diameter, which were located over the grid retaining the sample attached to the frame of the original sample holder. The height from the sample surface to the corner tube was $9 \mathrm{~mm}$ (up to centroid) and from the sample surface to the central tube was $10 \mathrm{~mm}$. One of the tube was situated in the center of the sample and the other was close to one corner. Two thermocouples (type K) were also located either on the sample surface and beneath the back surface, attached to aluminum slab as it is shown in Fig. 3. All specimens were tested in horizontal orientation using that modified holder.

(a)

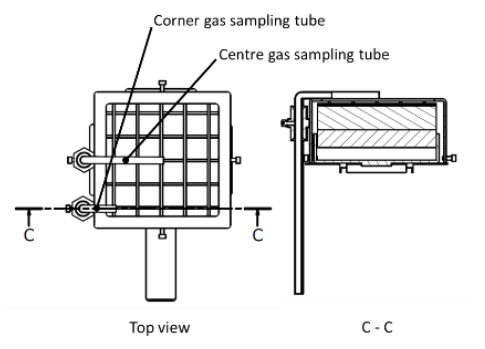

(b)

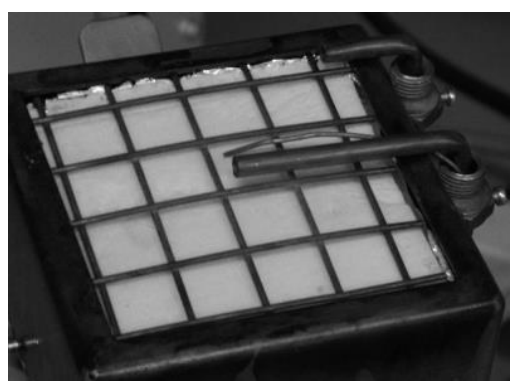

Fig. 2. a Upper view of placements of two gas-sampling tubes, $\mathbf{b}$ View of the modified horizontal specimen set up with a foam sample.

Figure 3 shows the position of tubes and surface thermocouple and the differences between the sample holder [4] and the modified one. 

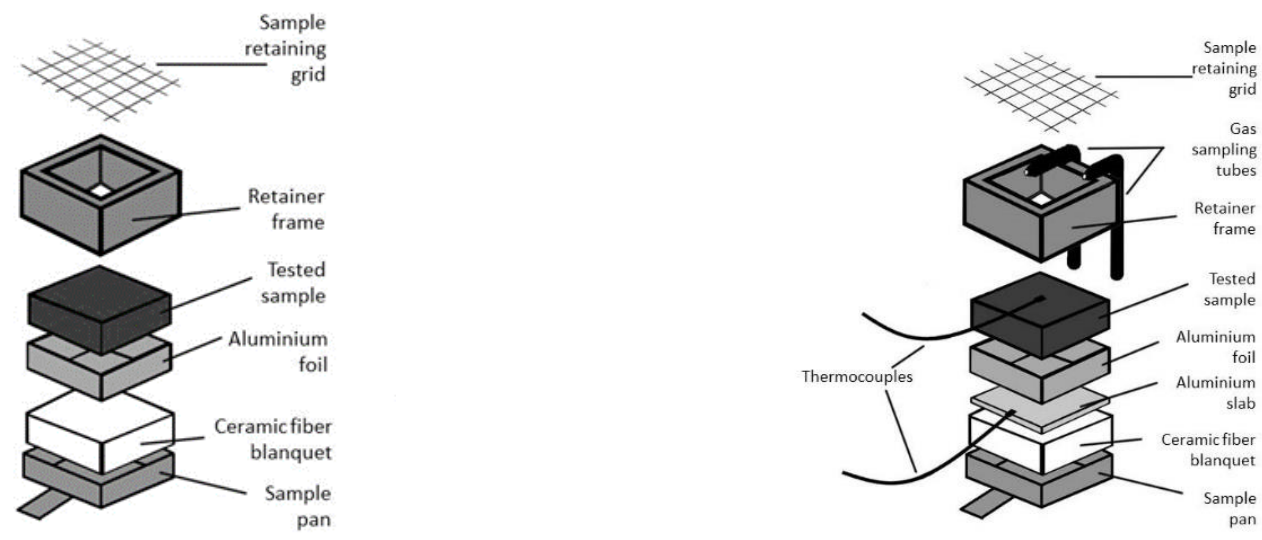

Fig. 3. a Draw of horizontal specimen set-up according to ASTM E 1354 04a [4], b Draw of modified horizontal specimen set-up with the thermocouples, aluminium slab and gas sampling tubes.

In this work, we assumed that between sample surface and flame leading edge there is a vessel, mixing layer, in which oxygen concentration depends on consumption from the flame and displacement due to mass flow from the sample (refer to Fig. 4 a). The yield of $\mathrm{O}_{2}$ was measured by the TESTO -350XL apparatus (on volume unit) in the mixing layer as it is shown in Fig. 4 b, where also we can see the complete system for collecting gas at mixing layer position. That flow was soot-filtered to avoid large particles blocking gas-sampling probes. In order to connect sampling probe and sampling tubes a vessel was placed between soot filter and the gas-sampling probe. Each tube had its own circuit and the gas analyzer received both entries. The volumetric flow extracted by the gas analyzer was $1.25 \times 10^{-5} \mathrm{~m}^{3} \mathrm{~s}^{-1}$. The external gas analyzer had been calibrated using oxygen and carbon dioxide mixtures $\left(\mathrm{O}_{2}: 0 \%, 1.41 \%, 5.02 \%\right.$ and $\left.\mathrm{CO}_{2}: 16.91 \%, 38.5 \%\right)$.

(a)

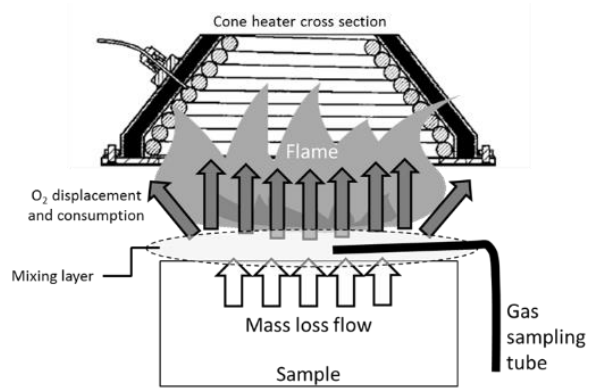

(b)

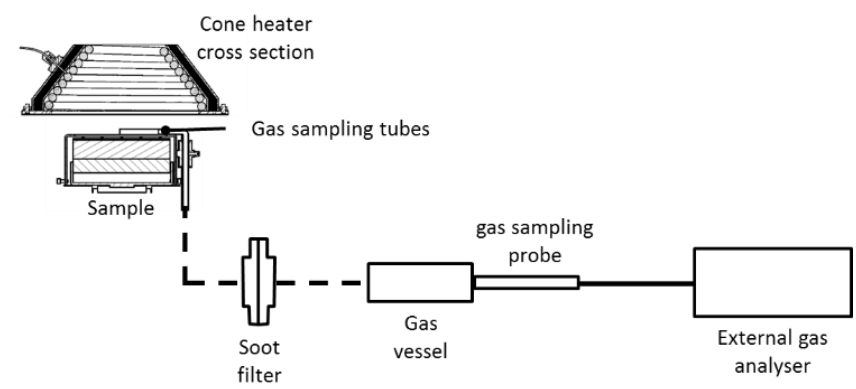

Fig. 4. a Detailed figure of the area where combustion gases are collected by the external gas analyser, b Sampling gas diagram

Before the tests, we check the flow of the released gases from the sample in the cone to verify if the gas sampling tube layout was collecting air from the surrounding atmosphere and thus it would affect the results. By numerical modelling calculations of cone calorimeter conditions using Fluent ${ }^{\circledR}$ software, we modelled an ideal cone test where mass loss yields homogenously over the entire surface. As inlet boundary condition, the released gas temperature was $375^{\circ} \mathrm{C}$ and the mass flux $10^{-5} \mathrm{Kg} \mathrm{s}^{-1}$. In addition, a temperature of cone heater of $720^{\circ} \mathrm{C}$ was used. Finally, we suppose that material released a gas fuel composed by ethylene, which mixed with the environmental air. Technical information about the setup of computational model is shown in next Table 4.

Table 4. Technical information about computational modelling.

$\begin{array}{ll}\text { CFD code } & \text { Fluent } \mathbf{1 3 . 0 . 0} \\ \text { Mesh } & 682581 \text { tetrahedral cells } \\ \text { Viscosity } & \text { Laminar (Sutherland model of two constants, C1:1.72e-5, C2:293, viscous heating) }\end{array}$


Radiation

Species model

Energy equation

Outlet

General
Discrete ordinates ( 6 theta and phi angles, 4 Theta an phi pixels, 10 Flow interactions per Radiation interaction)

Species transport (Volumetric reactions, inlet diffusion, aggressiveness factor 0.5)

On

Pressure outlet -90/Pa

Pressure based, stationary, gravity $\left(0,0,-9.8 \mathrm{~m}^{-1} \mathrm{~s}^{-2}\right)$

We performed stationary analysis to capture the characteristics of peak occurrence. Figure 5 a shows a contour of velocity profile in a plane that cut the holder vertically, including the effect of extraction from exhaust tube and Fig. $5 \mathrm{~b}$ the viscosity of the released gases.

(a)

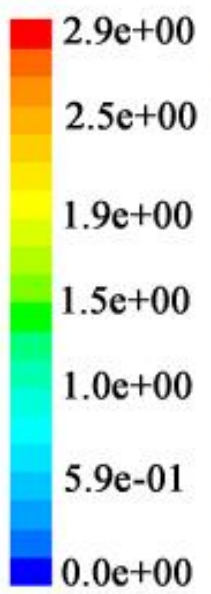

(b)

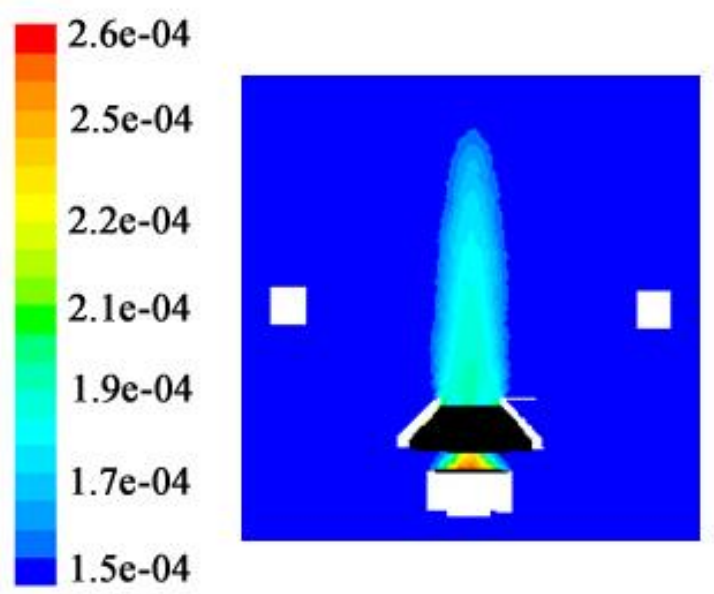

Fig. 5. a Contours of velocity $/ \mathrm{m} \mathrm{s}^{-1}$, b Viscosity $/ \mathrm{kg} \mathrm{m}^{-1}$

We evaluate only oxygen concentration values due to the displacement made by mass flux released. At stationary regime characterized by previous data quoted before, we obtained Fig. 6 for oxygen concentration across a sampling line over the diagonal of the sample, from tube-sampling location to the opposite corner.

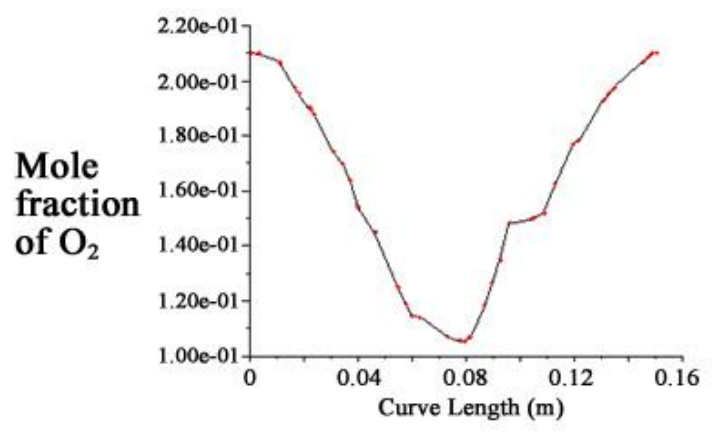

Fig. 6. Oxygen profile across the diagonal $10 \mathrm{~mm}$ over the surface

We can observe that concentration over the corner was close to $21 \%$ and, at the centre of the sample, this concentration decreases up to $10.6 \%$. The model showed a profile of oxygen concentration where in the centre of the sample is lower than in the edges of the sample, i.e. the centre of the sample shows a decrease of the oxygen level due to the combustion of the sample. As the contribution of the oxygen concentration from surrounding atmosphere was demonstrated to be insignificant, we can consider that samples are collecting oxygen concentration in the mixture layer adequately.

\section{Results}

Firstly, we evaluated if measurements of sampling gas devices were affecting the global results of the tests, therefore we define a ratio between collected mass flow by the gas sensor $\dot{m}_{s}$ and the mass flow of the burned samples $\dot{m}$. which we denoted as $\frac{2 \dot{m}_{S}}{\dot{m}_{\text {peak }}}$ and averaged, $\frac{2 \dot{m}_{S}}{\dot{m}_{\text {avg }}}$ for maximum conditions and average respectively Table 5. For that, we supposed that 
the temperature was the averaged surface temperature using a thermocouple during flame regime and gas sampled was a perfect gas, with nitrogen as main component.

Table 5. Data used to obtain sampling mass flow $\left(\dot{\mathrm{m}}_{\mathrm{s}}\right)$ and both average and peak mass loss for each material at different incident heat fluxes in cone calorimeter

\begin{tabular}{|c|c|c|c|c|c|c|c|}
\hline Material & $H_{\text {flux }} \cdot{ }_{\text {cone }} / \mathrm{kW} \mathrm{m}^{-2}$ & $\overline{\mathrm{T}} /{ }^{\circ} \mathrm{C}$ & $\dot{\mathrm{m}}_{\mathrm{avg}} \times 10^{-5} / \mathrm{kg} \mathrm{s}^{-1}$ & $\dot{\mathrm{m}}_{\text {peak }} \times 10^{-5} / \mathrm{kg} \mathrm{s}^{-1}$ & $\frac{2 \dot{\mathrm{m}}_{\mathrm{s}}}{\dot{\mathrm{m}}_{\mathrm{avg}}}$ & $\frac{2 \dot{\mathrm{m}}_{\mathrm{s}}}{\dot{\mathrm{m}}_{\text {peak }}}$ & $\frac{\dot{\mathrm{q}}}{\begin{array}{l}\text { peak } \\
\text { gas }\end{array}}$ \\
\hline \multirow{2}{*}{ Brushed fir } & 25 & 545.6 & $2.10 \pm 0.32$ & $7.16 \pm 0.83$ & $0.54_{-0.11}^{+0.10}$ & $0.16 \pm 0.01$ & $0.86 \pm 0.09$ \\
\hline & r 50 & 709.7 & $2.89 \pm 0.40$ & $10.13 \pm 1.12$ & $0.33_{-0.06}^{+0.05}$ & $0.09 \pm 0.01$ & $0.78 \pm 0.08$ \\
\hline \multirow{2}{*}{$\begin{array}{l}\text { Corrugated } \\
\text { cardboard }\end{array}$} & 25 & 488.4 & $1.84 \pm 0.29$ & $5.44 \pm 0.65$ & $0.66_{-0.14}^{+0.13}$ & $0.22 \pm 0.01$ & $0.79 \pm 0.08$ \\
\hline & 50 & 603.1 & $2.50 \pm 0.36$ & $8.44 \pm 0.95$ & $0.42 \pm 0.08$ & $0.13 \pm 0.01$ & $0.84 \pm 0.08$ \\
\hline \multirow{2}{*}{$\begin{array}{l}\text { PVC wall } \\
\text { panelling }\end{array}$} & $* 25$ & 402.9 & $0.75 \pm 0.18$ & $3.29 \pm 0.44$ & $1.83_{-0.70}^{+0.65}$ & $0.42_{-0.06}^{+0.04}$ & - \\
\hline & 50 & 587.7 & $2.33 \pm 0.34$ & $9.14 \pm 1.02$ & $0.46_{-0.09}^{+0.08}$ & $0.12 \pm 0.01$ & $1.17 \pm 0.12$ \\
\hline \multirow{2}{*}{ Nylon 66} & $* 25$ & 249.2 & $5.83 \pm 0.817$ & $2.76 \pm 0.387$ & $0.21_{-0.14}^{+0.04}$ & $0.44_{-0.10}^{+0.04}$ & - \\
\hline & $\underline{50}$ & 592.0 & $10.80 \pm 1.52$ & $10.74 \pm 2.44$ & $0.09_{-0.06}^{+0.02}$ & $0.06_{-0.01}^{+0.005}$ & $0.65 \pm 0.07$ \\
\hline \multirow{2}{*}{$\begin{array}{l}\text { Polyuretha } \\
\text { ne foam }\end{array}$} & 25 & 447.3 & $2.32 \pm 0.34$ & $6.43 \pm 0.75$ & $0.56_{-0.11}^{+0.10}$ & $0.20 \pm 0.01$ & $0.43 \pm 0.04$ \\
\hline & 50 & 574.7 & $3.01 \pm 0.41$ & $14.12 \pm 1.52$ & $0.36 \pm 0.06$ & $0.08 \pm 0.01$ & $0.79 \pm 0.08$ \\
\hline \multirow{2}{*}{ PET } & 25 & 501.1 & $5.93 \pm 0.83$ & $13.66 \pm 1.91$ & $0.21_{-0.14}^{+0.04}$ & $0.44_{-0.10}^{+0.04}$ & $0.92 \pm 0.09$ \\
\hline & 50 & 668.8 & $8.39 \pm 1.17$ & $18.57 \pm 2.60$ & $0.09_{-0.06}^{+0.20}$ & $0.06_{-0.01}^{+0.005}$ & $1.46 \pm 0.11$ \\
\hline
\end{tabular}

*No ignition takes place. $\overline{\mathrm{T}}$ for test without ignition is the temperature of the surface during the test

The percent of sampling gas from the corner and center tubes reached values from $20 \%$ to $66 \%$ when comparing with average mass loss and about $8 \%$ to $22 \%$ when peak takes place. These values were only indicatives because sampling system extracted also some products of combustion and rounding air. As a result, we estimated the value of mixture density at the point of maximum difference between density of nitrogen gas and mixture and this was in the range of $0.9\left(16 \% \mathrm{CO}_{2}\right.$, $\left.32 \% \mathrm{H}_{2} \mathrm{O}, 52 \% \mathrm{~N}_{2}\right)$ to $1.08\left(16 \% \mathrm{CO}_{2}, 8 \% \mathrm{H}_{2} \mathrm{O}, 76 \% \mathrm{~N}_{2}\right)$ times the density of nitrogen.

Secondly, we repeated cone tests for each material at both radiance levels to analyze if the gas sampling tubes were modifying their fire behavior and we compared results with tubes $\left(q_{g}^{\dot{g} a s}\right)$ and without them $\left(q_{\text {cone }}\right)$. Last column of Table $5\left(\frac{\dot{q} \text { gas }}{\dot{q} \text { peak }}\right)$ is the ratio between HRR peaks of both test conditions. It seems logic that it is linearly related at peak of heat release with the ratio of burning rates for both but it is interesting that the relation between burning rate and mass loss rate depends on sample analyzed. Thereby, if we consider an error in heat release rate of $5 \%$ that ratio has an error value of $10 \%$ and the values observed (last column) match pretty well with our supposed mass flow at the peak $\left(\frac{2 \mathrm{~m}_{\mathrm{s}}}{\dot{\mathrm{m}}_{\text {peak }}}\right)$ except for polyurethane sample at $25 \mathrm{~kW} \mathrm{~m}^{-2}$. Brushed fir sample contained significant quantities of water vapor as moisture and showed a higher ratio for $25 \mathrm{~kW} \mathrm{~m}^{-2}$ than for $50 \mathrm{~kW} \mathrm{~m}^{-2}$. The rest of the samples, which had a negligible moisture content provided higher ratios at higher irradiance levels. PVC panelling was a singular case owing to the release of hydrogen chloride therefore its heat release rates were higher with the modified holder.

Mass residue and reaction rate

The main experimental argument sustaining the non-oxygen significance at mixing-layer is the correlation between the percent of total mass loss in TG tests at inert atmospheres (up to $900{ }^{\circ} \mathrm{C}$ [17]) and standard cone tests, although TG and cone calorimetric have different principles. Each material was tested in both scales in order to find out and make a comparison between both parameters and verify the generalization of the former claim. The mass of the sample and reaction rate of TGA are much smaller in comparison with the cone calorimetric test. In order to establish an adequate comparison between both type of tests, the mass during the test and final residue are expressed in $\%$ and the mass loss rate was divided by the initial mass to obtain the rhythm in s-1. Table 6 shows the percentage of the final mass residue of the tests and Table 7 indicates the values of maximum reaction rate, i.e. the maximum values of mass loss rate curves are showed in Figures 7 to 12. 
Table 6. Percent of mass residue (\%) from different analysis performed

\begin{tabular}{lllll}
\hline \multirow{2}{*}{ Material } & \multicolumn{2}{c}{ TG test } & \multicolumn{2}{c}{ Cone calorimetric test } \\
\cline { 2 - 5 } & $\mathrm{N}_{2}$ & Air & $25 \mathrm{~kW} \mathrm{~m}^{-2}$ & $50 \mathrm{~kW} \mathrm{~m}^{-2}$ \\
\hline Brushed fir & 19.89 & 10.54 & 21.21 & 14.89 \\
Corrugated cardboard & 20.27 & 7.70 & 57.32 & 36.34 \\
PVC wall panelling & 36.26 & 11.34 & $* 66.49$ & 11.89 \\
Nylon 66 & 0.06 & 0.01 & $* 99.44$ & 0.00 \\
Polyurethane foam & 10.40 & 0.00 & 53.64 & 36.50 \\
PET & 14.02 & 0.00 & 70.33 & 0.00 \\
\hline
\end{tabular}

Table 7. Maximum reaction rate $\left(\mathrm{s}^{-1}\right)$ from different analysis performed

\begin{tabular}{lllll}
\hline \multirow{2}{*}{ Material } & \multicolumn{2}{c}{ TG test } & \multicolumn{2}{c}{ Cone calorimetric test } \\
\cline { 2 - 5 } & $\mathrm{N}_{2}$ & Air & $25 \mathrm{~kW} \mathrm{~m}^{-2}$ & $50 \mathrm{~kW} \mathrm{~m}^{-2}$ \\
\hline Brushed fir & $1.94 \mathrm{E}-3$ & $3.88 \mathrm{E}-3$ & $8.38 \mathrm{E}-4$ & $1.33 \mathrm{E}-3$ \\
Corrugated cardboard & $2.19 \mathrm{E}-3$ & $2.85 \mathrm{E}-3$ & $4.38 \mathrm{E}-3$ & $9.69 \mathrm{E}-3$ \\
PVC wall panelling & $2.47 \mathrm{E}-3$ & $2.44 \mathrm{E}-3$ & $* 1.24 \mathrm{E}-3$ & $4.75 \mathrm{E}-3$ \\
Nylon 66 & $3.50 \mathrm{E}-3$ & $3.69 \mathrm{E}-3$ & $* 4.72 \mathrm{E}-4$ & $1.43 \mathrm{E}-3$ \\
Polyurethane foam & $1.58 \mathrm{E}-3$ & $1.04 \mathrm{E}-3$ & $3.61 \mathrm{E}-3$ & $9.20 \mathrm{E}-3$ \\
PET & $3.34 \mathrm{E}-3$ & $3.41 \mathrm{E}-3$ & $7.31 \mathrm{E}-4$ & $9.53 \mathrm{E}-4$ \\
\hline
\end{tabular}

We can see in Table 6 that the percent of mass residue at air atmosphere in TG are shorter than those ones at nitrogen atmosphere. In cone tests at 25 and $50 \mathrm{~kW} \mathrm{~m}^{-2}$ irradiance levels, there was a smaller percent of mass residue as irradiance level increases.

The reaction rates, displayed in Table 7, show higher reaction rates in TG tests, under both atmospheres, for brushed fir, Nylon and PET. By the contrast, corrugated cardboard, PVC wall panelling and PUR foam shown higher rates in cone when ignition takes, specially under $50 \mathrm{~kW} \mathrm{~m}^{-2}$ irradiance level.

Figures 7 to 12 show the mass loss and their rates for each material in TG test (both atmospheres) and cone calorimeter (both incident flux).

(a)

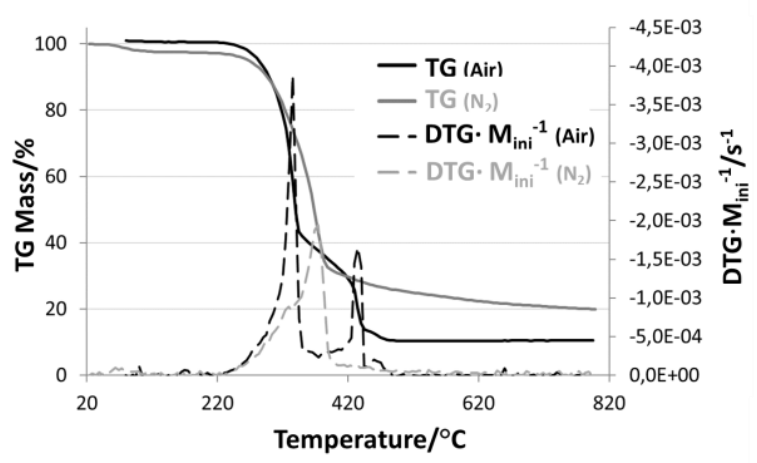

(b)

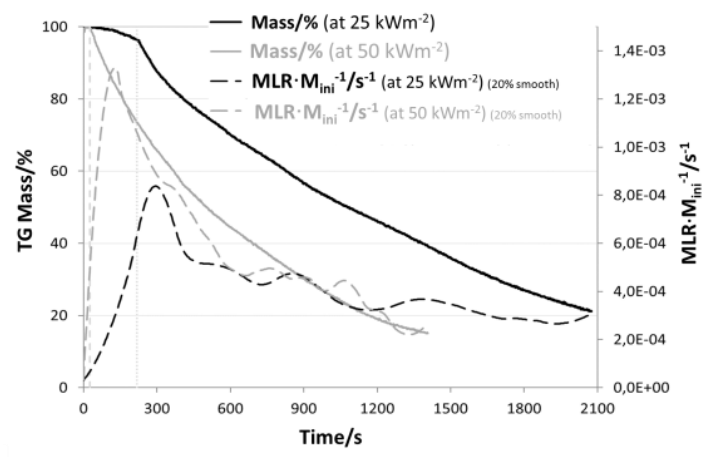

Fig. 7. Mass loss and its rate for brushed fir. a TG test in $\mathrm{N}_{2}$ and air atmosphere. b Cone calorimeter test, incident flux of 25 and $50 \mathrm{~kW} \mathrm{~m}^{-2}$. In $\mathbf{b}$ vertical dashed lines means sample ignition.

(a)

(b) 

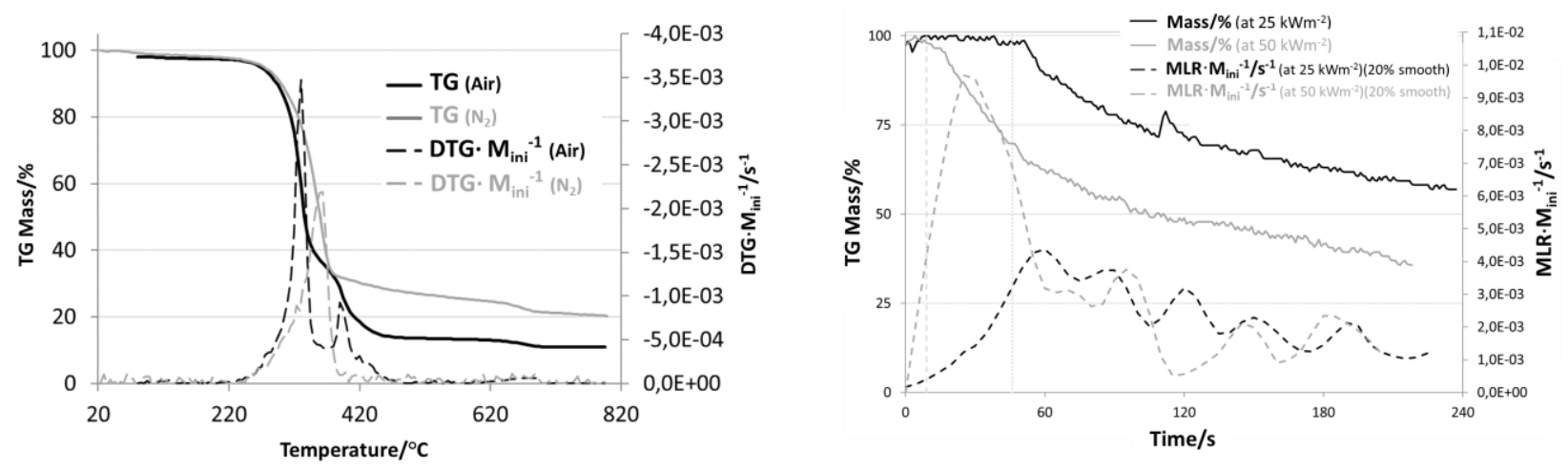

Fig. 8. Mass loss and its rate for corrugated cardboard. a TG test in $\mathrm{N}_{2}$ and air atmosphere. b Cone calorimeter test, incident flux of 25 and $50 \mathrm{~kW} \mathrm{~m}^{-2}$. In $\mathbf{b}$ vertical dashed lines means sample ignition.

(a)

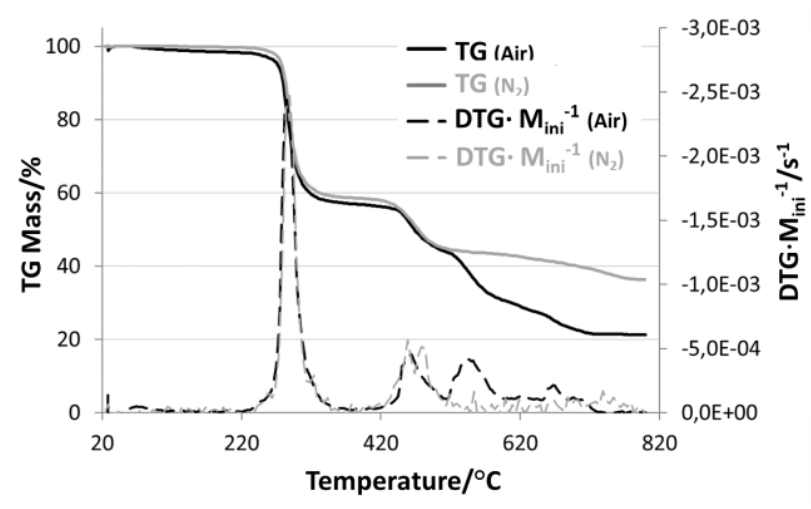

(b)

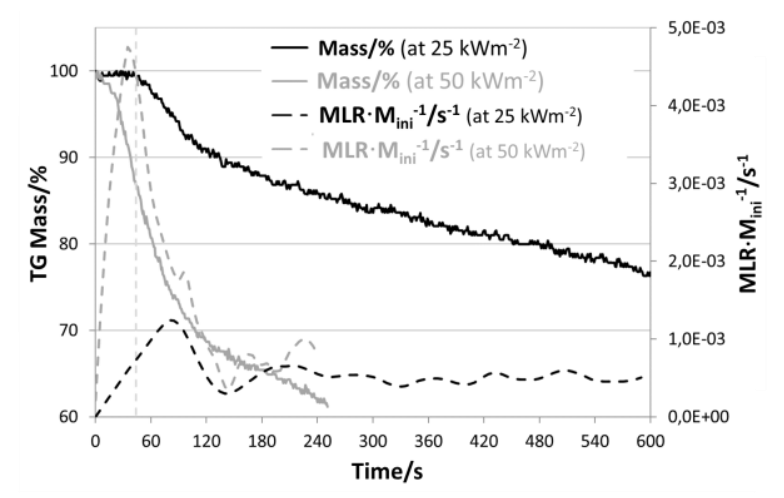

Fig. 9. Mass loss and its rate for PVC wall panelling. a TG test in $\mathrm{N}_{2}$ and air atmosphere. b Cone calorimeter test, incident flux of 25 and $50 \mathrm{~kW} \mathrm{~m}^{-2}$. In $\mathbf{b}$ vertical dashed lines means sample ignition. (In this case there was ignition only under a flux of $50 \mathrm{~kW} \mathrm{~m}^{-2}$ )

(a)

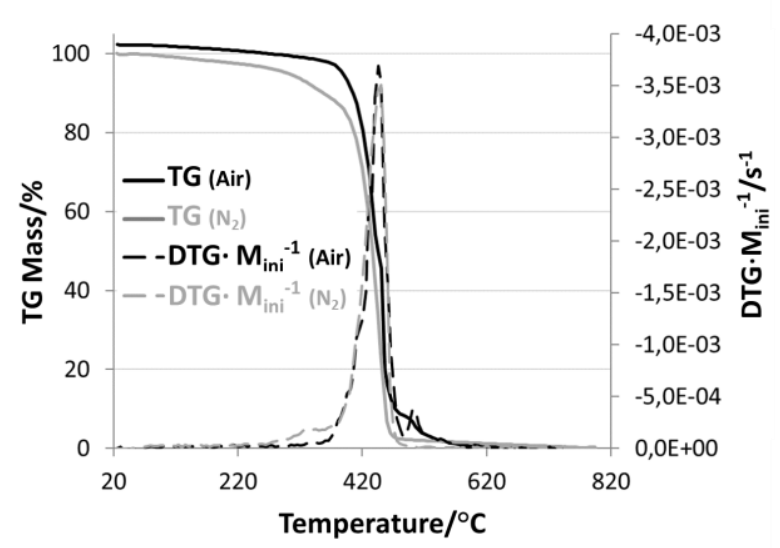

(b)

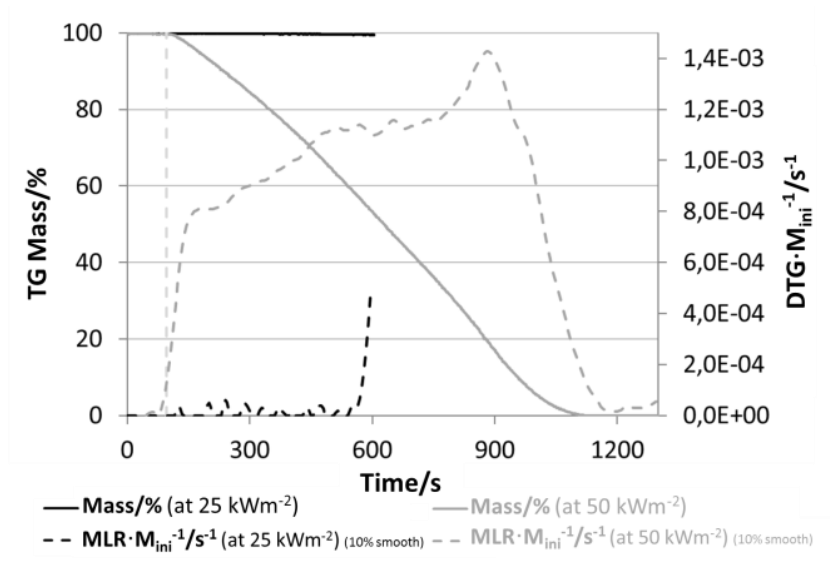

Fig. 10. Mass loss and its rate for Nylon 66. a TG test in $\mathrm{N}_{2}$ and air atmosphere. b Cone calorimeter test, incident flux of 25 and $50 \mathrm{~kW} \mathrm{~m}^{-2}$. In $\mathbf{b}$ vertical dashed lines means sample ignition. (In this case there was ignition only under a flux of $50 \mathrm{~kW}$ $\mathrm{m}^{-2}$ )

(a) 

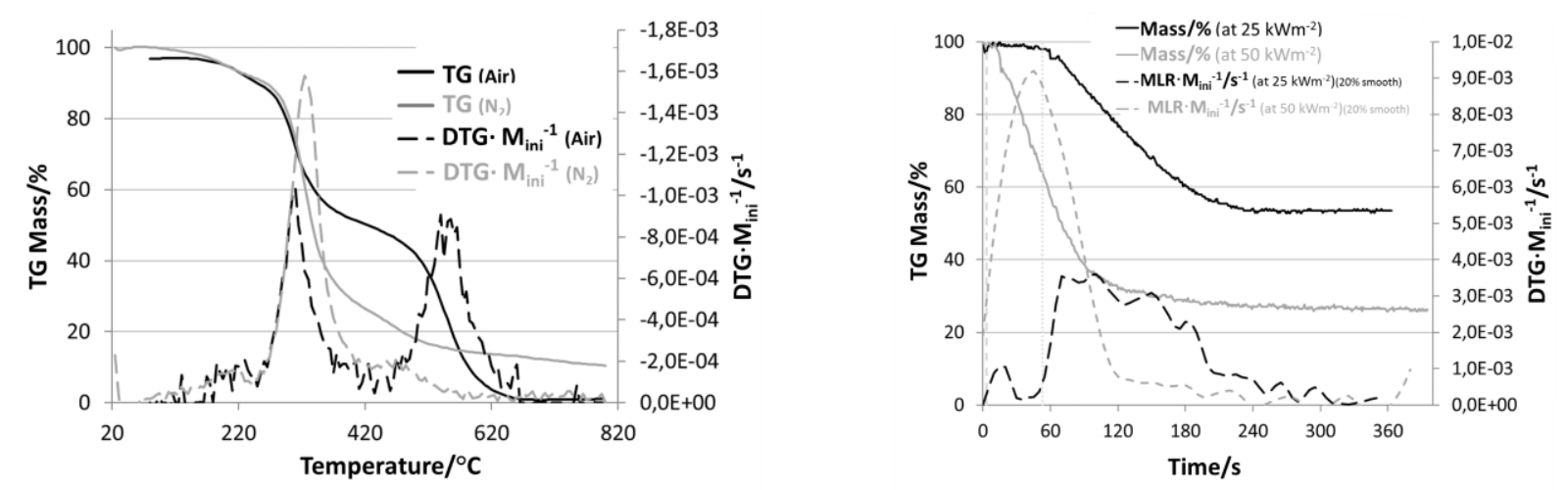

Fig. 11. Mass loss and its rate for polyurethane foam. a TG test in $\mathrm{N}_{2}$ and air atmosphere. b Cone Calorimeter test, incident flux of 25 and $50 \mathrm{~kW} \mathrm{~m}^{-2}$. In $\mathbf{b}$ vertical dashed lines means sample ignition.

(a)

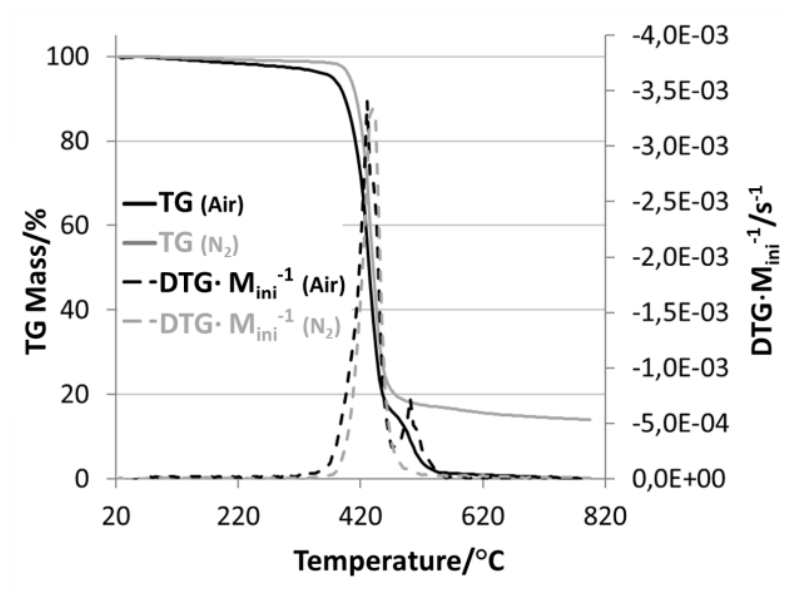

(b)

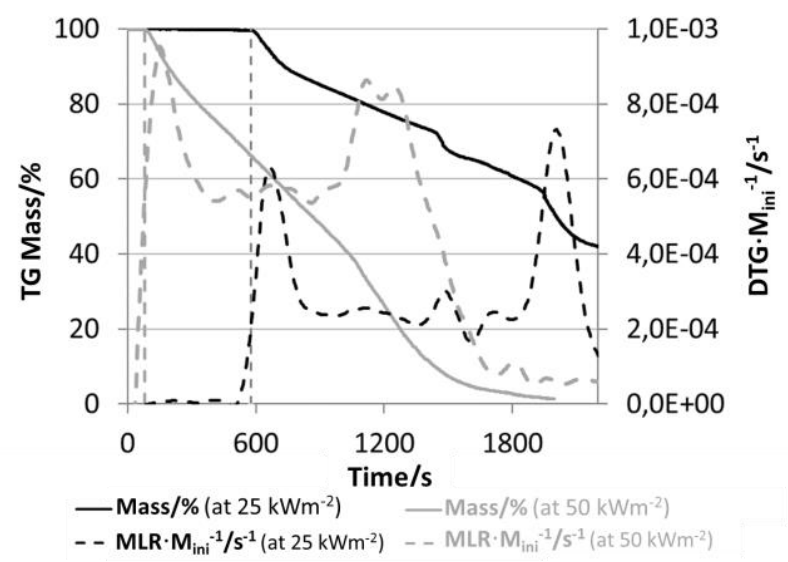

Fig. 12. Mass loss and its rate for PET. a TG test in $\mathrm{N}_{2}$ and air atmosphere. b Cone calorimeter test, incident flux of 25 and $50 \mathrm{~kW} \mathrm{~m}^{-2}$. In b vertical dashed lines means sample ignition.

Oxygen and carbon dioxide values

Tables 8 and 9 summarize the values of concentration of $\mathrm{O}_{2}$ and $\mathrm{CO}_{2}$ in the mixture layer. The error of the external analyzer was considered respectively within \pm 0.2 for $\mathrm{O}_{2}$ and \pm 0.42 for $\mathrm{CO}_{2}$, respectively.

Table 8. Percent of lowest $\mathrm{O}_{2}$ concentrations measured during the test from different analysis performed (error \pm 0.2 )

\begin{tabular}{|c|c|c|c|c|c|c|}
\hline \multirow{3}{*}{ Material } & \multicolumn{4}{|c|}{ External gas analyser } & \multicolumn{2}{|c|}{ Cone gas analyser } \\
\hline & \multicolumn{2}{|c|}{ Centre tube } & \multicolumn{2}{|c|}{ Corner tube } & \multirow{2}{*}{$25 \mathrm{~kW} \mathrm{~m}^{-2}$} & \multirow{2}{*}{$50 \mathrm{~kW} \mathrm{~m}^{-2}$} \\
\hline & $25 \mathrm{~kW} \mathrm{~m}^{-2}$ & $50 \mathrm{~kW} \mathrm{~m}^{-2}$ & $25 \mathrm{~kW} \mathrm{~m}^{-2}$ & $50 \mathrm{~kW} \mathrm{~m} \mathrm{~m}^{-2}$ & & \\
\hline Brushed fir & 5.47 & 4.82 & 17.96 & 17.81 & 20.79 & 20.69 \\
\hline Corrugated cardboard & 15.93 & 14.07 & 18.76 & 18.40 & 20.81 & 20.74 \\
\hline PVC wall panelling & $* 20.74$ & 19.49 & $* 20.63$ & 19.74 & $* 21.06$ & 21.28 \\
\hline Nylon 66 & $* 21.04$ & 0.00 & $* 21.04$ & 0.00 & $* 20.93$ & 18.85 \\
\hline Polyurethane foam & 5.36 & 0.36 & 19.34 & 16.54 & 20.86 & 20.50 \\
\hline PET & 0.00 & 0.17 & 5.17 & 1.37 & 20.28 & 20.06 \\
\hline
\end{tabular}

Table 9. Percent of highest $\mathrm{CO}_{2}$ concentrations measured during the test from different analysis performed (error \pm 0.42 ) 


\begin{tabular}{|c|c|c|c|c|c|c|}
\hline \multirow{3}{*}{ Material } & \multicolumn{4}{|c|}{ External gas analyser } & \multicolumn{2}{|c|}{ Cone gas analyser } \\
\hline & \multicolumn{2}{|c|}{ Centre tube } & \multicolumn{2}{|c|}{ Corner tube } & \multirow{2}{*}{$25 \mathrm{~kW} \mathrm{~m}^{-2}$} & \multirow{2}{*}{$50 \mathrm{~kW} \mathrm{~m}^{-2}$} \\
\hline & $25 \mathrm{~kW} \mathrm{~m}^{-2}$ & $50 \mathrm{~kW} \mathrm{~m}^{-2}$ & $25 \mathrm{~kW} \mathrm{~m}^{-2}$ & $50 \mathrm{~kW} \mathrm{~m}^{-2}$ & & \\
\hline Brushed fir & 11.47 & 11.94 & 2.25 & 2.36 & 0.20 & 0.26 \\
\hline Corrugated cardboard & 3.74 & 5.11 & 1.65 & 1.92 & 0.18 & 0.24 \\
\hline PVC wall panelling & $* 0.66$ & 1.12 & $* 0.72$ & 0.62 & $* 0.06$ & 0.17 \\
\hline Nylon 66 & $* 0.14$ & 11.78 & $* 0.03$ & 11.98 & $* 0.06$ & 0.80 \\
\hline Polyurethane foam & 9.70 & 15.24 & 0.06 & 6.46 & 0.13 & 0.37 \\
\hline PET & 28.34 & 14.51 & 31.38 & 19.16 & 0.64 & 0.85 \\
\hline
\end{tabular}

As it was expected, due to its position, the cone gas analyzer was not suitable for measure gas concentrations in the mixture layer, i.e. $\mathrm{O}_{2}$ and $\mathrm{CO}_{2}$ levels slightly changed their initial values.

In order to compare and discuss the results obtained for different incident heat fluxes, values of Table 8 and 9 were normalized by dividing by the heat release rate peak (HRR) of each test. We estimated an error of the $10 \%$ in the values obtained by $\mathrm{O} 2$ depletion [24].

Table 10 and 11 show normalized values of $\mathrm{O}_{2}$ and $\mathrm{CO}_{2}$ in the mixture layer.

Table 10. Percent of lowest $\mathrm{O}_{2}$ normalized by heat release peak

\begin{tabular}{llccc}
\hline \multirow{2}{*}{ Material } & \multicolumn{4}{c}{ External gas analyser } \\
\cline { 2 - 5 } & \multicolumn{3}{c}{ Centre tube } & \multicolumn{2}{c}{ Corner tube } \\
& $25 \mathrm{~kW} \mathrm{~m}^{-2}$ & $50 \mathrm{~kW} \mathrm{~m}^{-2}$ & $25 \mathrm{~kW} \mathrm{~m}^{-2}$ & $50 \mathrm{~kW} \mathrm{~m}^{-2}$ \\
\hline Brushed fir & $1.46 \pm 2.21$ & $8.32 \pm 1.43$ & $17.16 \pm 0.64$ & $18.46 \pm 0.39$ \\
Corrugated cardboard & $13.74 \pm 1.01$ & $14.03 \pm 0.90$ & $17,78 \pm 0.61$ & $18.43 \pm 0.44$ \\
PVC wall panelling & $*$ & $18.64 \pm 0.55$ & $*$ & $18.88 \pm 0.51$ \\
Nylon 66 & $*$ & $0.00 \pm 0.80$ & $*$ & $0.00 \pm 0.80$ \\
Polyurethane foam & $4.79 \pm 1.83$ & $11.58 \pm 1.03$ & $19.44 \pm 0.36$ & $18.75 \pm 0.30$ \\
PET & $12.39 \pm 0.82$ & $14.14 \pm 0.69$ & $14.53 \pm 0.65$ & $14.39 \pm 0.64$ \\
\hline
\end{tabular}

Table 11. Percent of higher $\mathrm{CO}_{2}$ concentrations normalized by heat release peak

\begin{tabular}{llccc}
\hline \multirow{2}{*}{ Material } & \multicolumn{3}{c}{ External gas analyser } \\
\cline { 2 - 5 } & \multicolumn{3}{c}{ Centre tube } & \multicolumn{2}{c}{ Corner tube } \\
\hline Brushed fir & $25 \mathrm{~kW} \mathrm{~m}^{-2}$ & $50 \mathrm{~kW} \mathrm{~m}^{-2}$ & $25 \mathrm{~kW} \mathrm{~m}^{-2}$ & $50 \mathrm{~kW} \mathrm{~m}^{-2}$ \\
Corrugated cardboard & $14.41 \pm 1.69$ & $9.35 \pm 1.09$ & $2.83 \pm 0.53$ & $1.85 \pm 0.34$ \\
PVC wall panelling & $5.32 \pm 0.82$ & $5.13 \pm 0.71$ & $2.35 \pm 0.52$ & $1.93 \pm 0.39$ \\
Nylon 66 & $*$ & $1.73 \pm 0.48$ & $*$ & $1.44 \pm 0.45$ \\
Polyurethane foam & $*$ & $2.14 \pm 0.21$ & $*$ & $2.18 \pm 0.21$ \\
PET & $10.05 \pm 1.21$ & $6.91 \pm 0.78$ & $0.06 \pm 0.00$ & $2.93 \pm 0.29$ \\
& $11.75 \pm 1.17$ & $4.73 \pm 0.47$ & $13.00 \pm 1.30$ & $6.25 \pm 0.63$ \\
\hline
\end{tabular}

*No ignition in cone test. Cases without ignition do not have an only main peak

By analyzing normalized values of $\mathrm{O}_{2}$ in the center of the holder, only corrugated cardboard and PET tended slightly to be independent of the value of the incident flux during flame regime, whereas $\mathrm{O}_{2}$ level decreased higher at $25 \mathrm{~kW} \mathrm{~m}^{-2}$ than at $50 \mathrm{~kW} \mathrm{~m}^{-2}$ in all other results. The $\mathrm{O}_{2}$ levels recorded by the external device located at the corner of the holder do not suffer huge changes due to the increase of the incident flux level.

There were differences of $\mathrm{CO}_{2}$ maximum concentrations between values at different irradiance levels which shown smaller values at lower severity for all materials apart of corrugated cardboard, where results seemed to be equal in both fluxes. When we analyzed normalized values at the center of the holder, we observed values obtained at lower irradiance levels were higher than those from cone tests with severe irradiance attacks.

Figures 13 to 18 show $\mathrm{O}_{2}(\%)$ and $\mathrm{CO}_{2}(\%)$ results, measured in the mixing layer by the external analyser. 
(a)

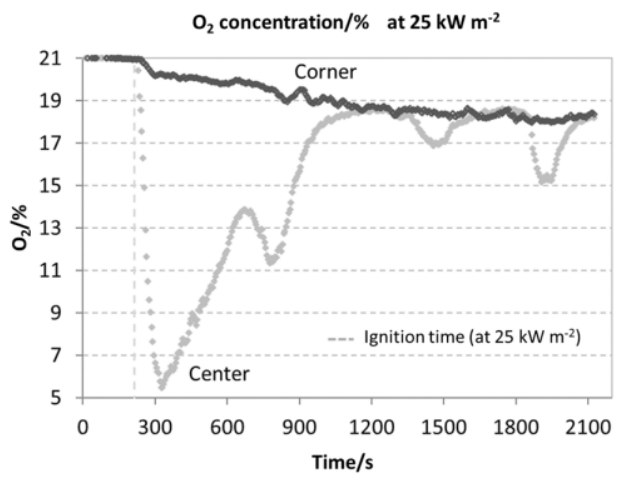

(c)

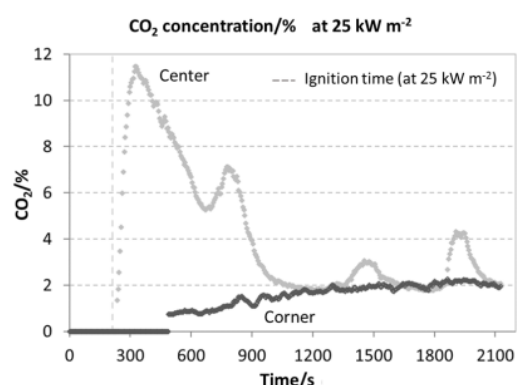

(b)

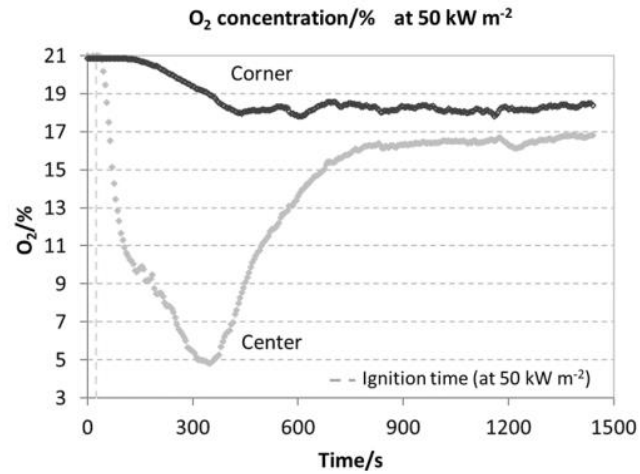

(d)

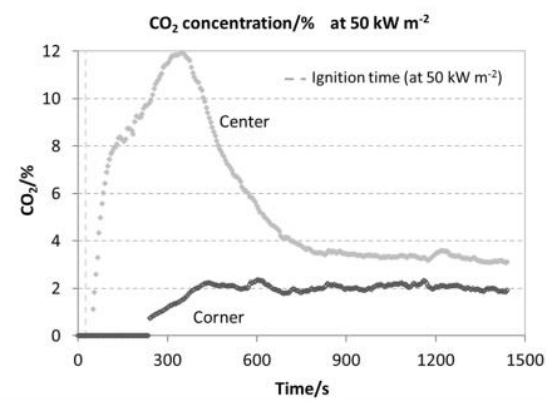

Fig. 13. Concentrations measured for brushed fir. a $\mathrm{O}_{2}$ concentration at incident flux of $25 \mathrm{~kW} \mathrm{~m}^{-2}$. b $\mathrm{O}_{2}$ concentration at incident flux of $50 \mathrm{~kW} \mathrm{~m}^{-2}$. c CO $\mathrm{CO}_{2}$ concentration at incident flux of $25 \mathrm{~kW} \mathrm{~m}^{-2}$. d CO $\mathrm{CO}_{2}$ concentration at incident flux of 50 $\mathrm{kW} \mathrm{m}{ }^{-2}$. Vertical dashed line corresponds to ignition in cone tests.

(a)

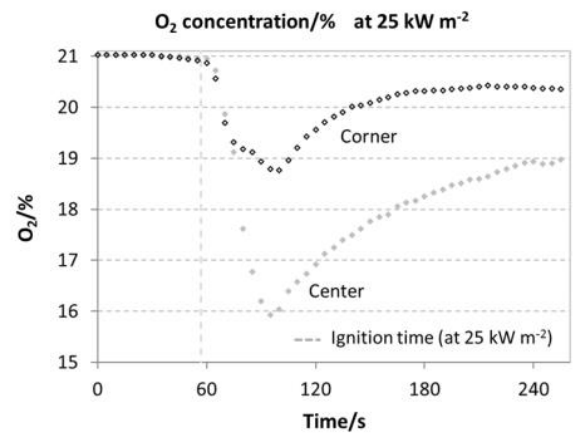

(c)

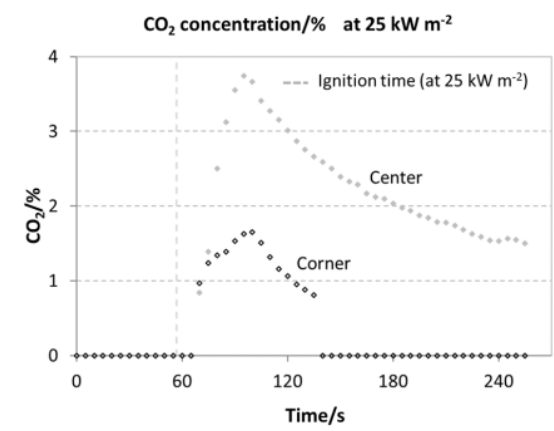

(b)

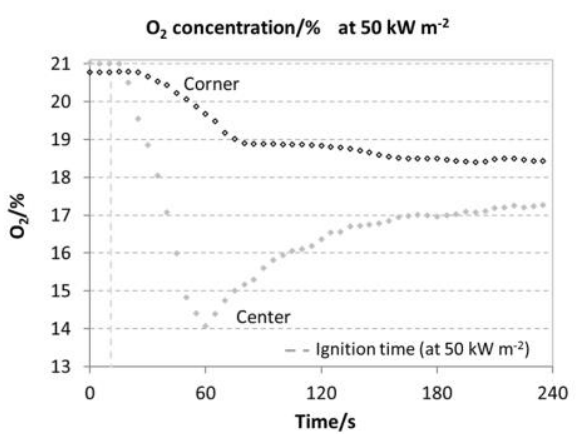

(d)

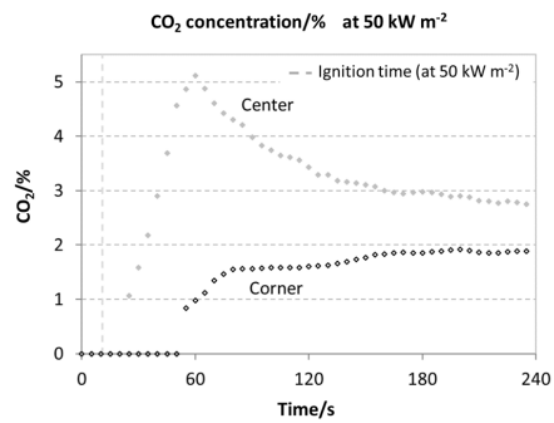

Fig. 14. Concentrations measured for corrugated cardboard. a $\mathrm{O}_{2}$ concentration at incident flux of $25 \mathrm{~kW} \mathrm{~m}$. b $\mathrm{O}_{2}$ concentration at incident flux of $50 \mathrm{~kW} \mathrm{~m}^{-2}$. $\mathbf{c ~ C O} 2$ concentration at incident flux of $25 \mathrm{~kW} \mathrm{~m}^{-2}$. d CO $\mathrm{CO}_{2}$ concentration at incident flux of $50 \mathrm{~kW} \mathrm{~m}^{-2}$. Vertical dashed line corresponds to ignition in cone tests.

(a)

(b) 


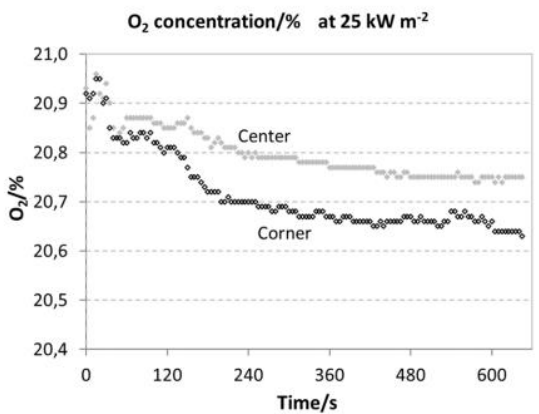

(c)

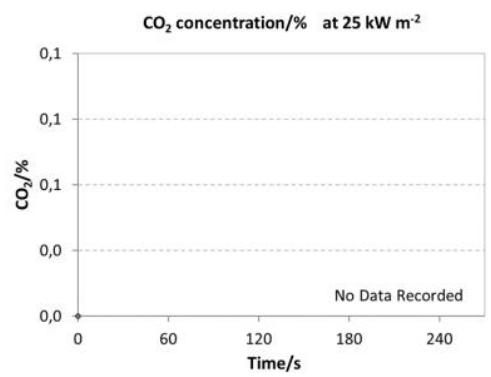

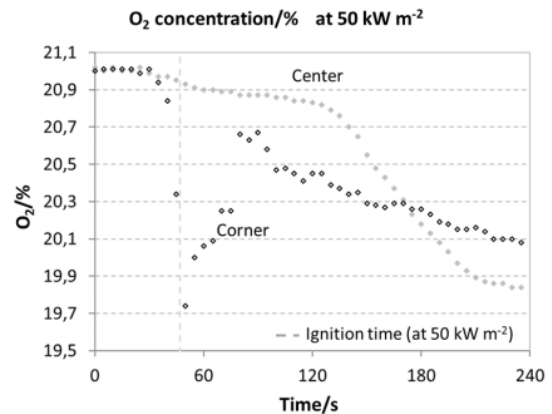

(d)

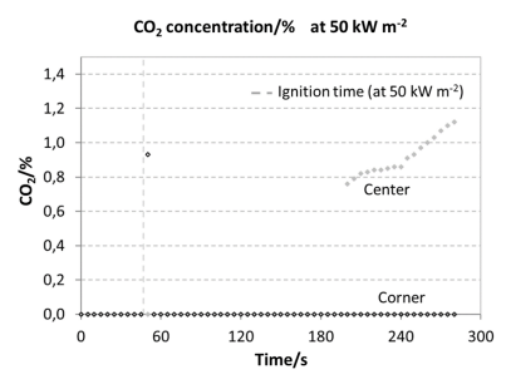

Fig. 15. Concentrations measured for $\mathrm{PVC}$ wall panelling. a $\mathrm{O}_{2}$ concentration at incident flux of $25 \mathrm{~kW} \mathrm{~m}^{-2}$. b $\mathrm{O}_{2}$ concentration at incident flux of $50 \mathrm{~kW} \mathrm{~m}{ }^{-2}$. $\mathrm{CO}_{2}$ concentration at incident flux of $25 \mathrm{~kW} \mathrm{~m}^{-2}$. $\mathbf{d ~ C O}_{2}$ concentration at incident flux of $50 \mathrm{~kW} \mathrm{~m}^{-2}$. Vertical dashed line corresponds to ignition in cone tests.

(a)

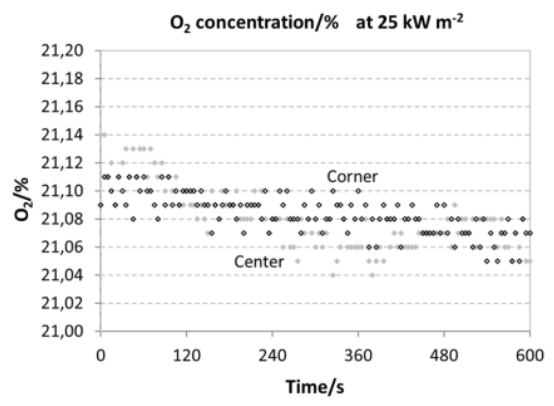

(c)

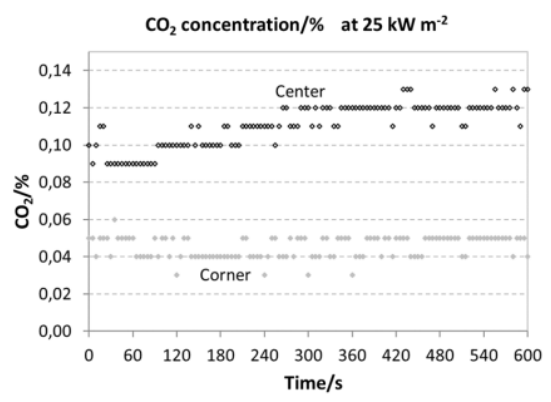

(b)

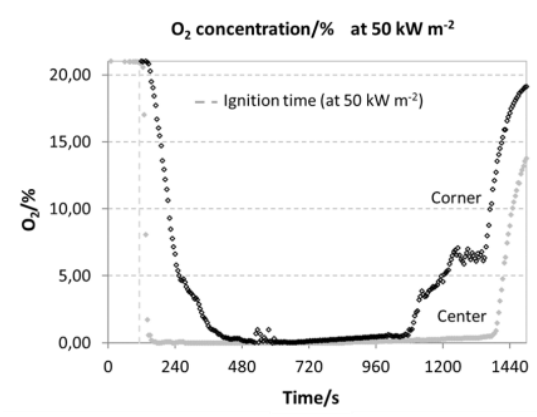

(d)

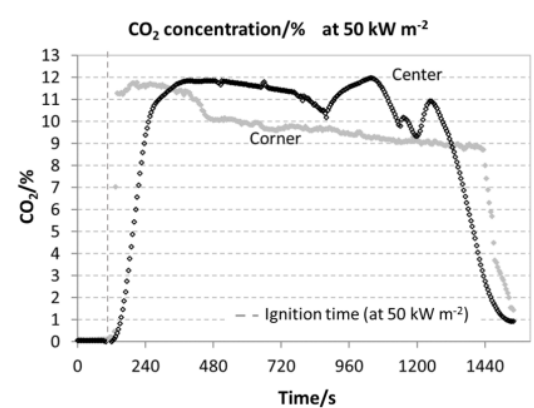

Fig. 16. Concentrations measured for Nylon 66. a $\mathrm{O}_{2}$ concentration at incident flux of $25 \mathrm{~kW} \mathrm{~m}{ }^{-2}$. b $\mathrm{O}_{2}$ concentration at incident flux of $50 \mathrm{~kW} \mathrm{~m}^{-2}$. $\mathrm{c} \mathrm{CO}_{2}$ concentration at incident flux of $25 \mathrm{~kW} \mathrm{~m}^{-2} . \mathbf{d ~ C O}_{2}$ concentration at incident flux of 50 $\mathrm{kW} \mathrm{m}{ }^{-2}$. Vertical dashed line corresponds to ignition in cone tests. 


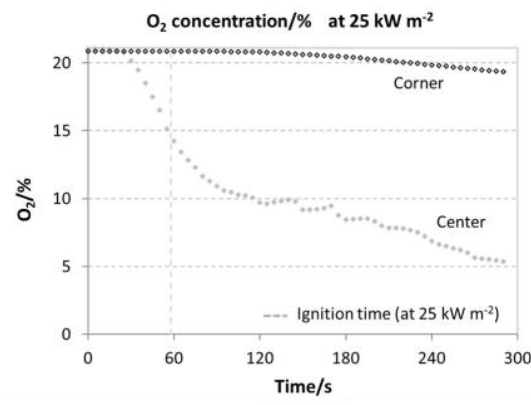

(c)

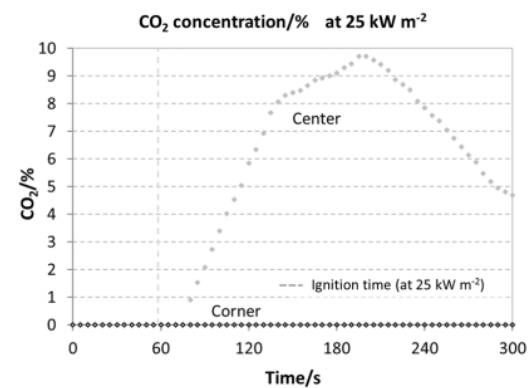

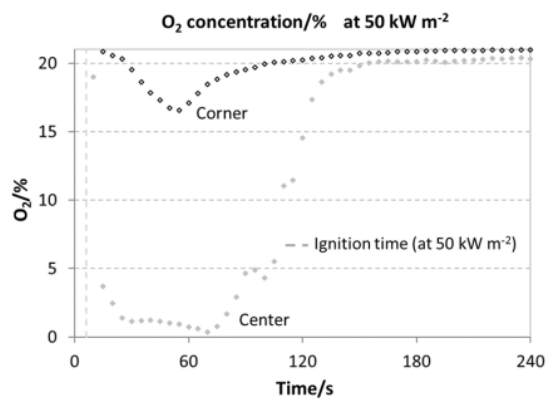

(d)

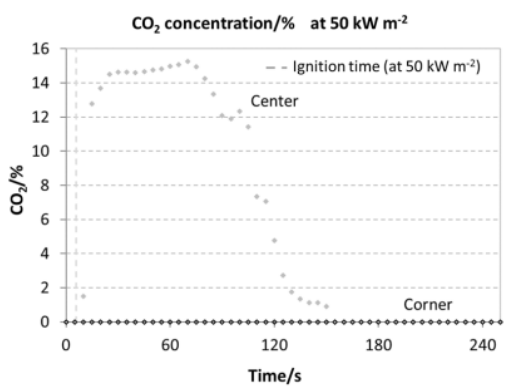

Fig. 17. Concentrations measured for polyurethane foam. a $\mathrm{O}_{2}$ concentration at incident flux of $25 \mathrm{~kW} \mathrm{~m}^{-2}$. b $\mathrm{O}_{2}$ concentration at incident flux of $50 \mathrm{~kW} \mathrm{~m}$. $\mathbf{c} \mathrm{CO}_{2}$ concentration at incident flux of $25 \mathrm{~kW} \mathrm{~m}^{-2}$. d CO $\mathrm{CO}_{2}$ concentration at incident flux of $50 \mathrm{~kW} \mathrm{~m}^{-2}$. Vertical dashed line corresponds to ignition in cone tests.

(a)

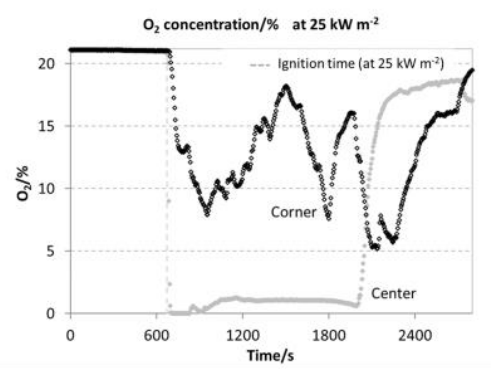

(c)

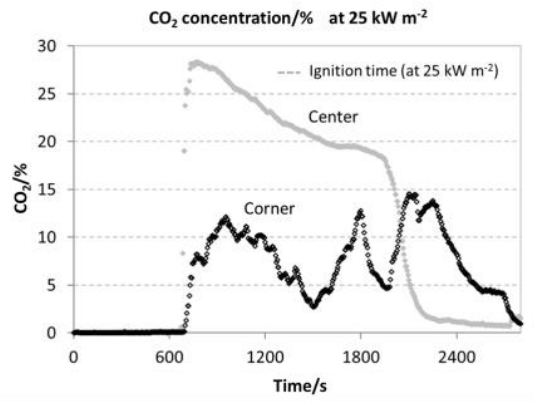

(b)

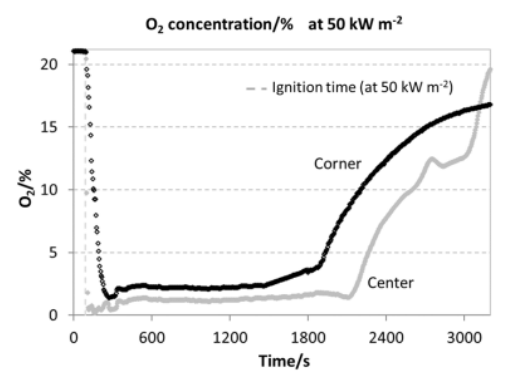

(d)

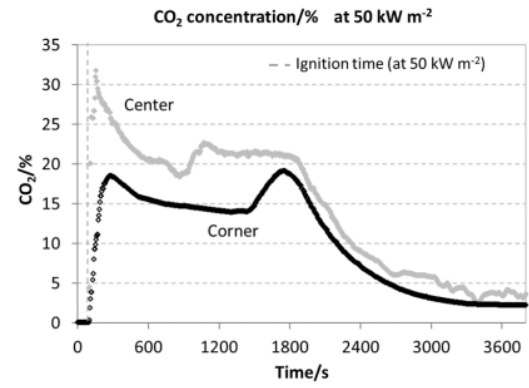

Fig. 18. Concentrations measured for PET. a $\mathrm{O}_{2}$ concentration at incident flux of $25 \mathrm{~kW} \mathrm{~m}^{-2}$. b $\mathrm{O}_{2}$ concentration at incident flux of $50 \mathrm{~kW} \mathrm{~m}^{-2}$. c $\mathrm{CO}_{2}$ concentration at incident flux of $25 \mathrm{~kW} \mathrm{~m}^{-2} \cdot \mathbf{d ~ C O}_{2}$ concentration at incident flux of $50 \mathrm{~kW} \mathrm{~m}$. Vertical dashed line corresponds to ignition in cone tests.

The yield of $\mathrm{O}_{2}$ observed at mixing layer showed that it was as small as it could be described this environment as inert only for PET at $25 \mathrm{~kW} \mathrm{~m}^{-2}$ and PET, Nylon and PUR foam at $50 \mathrm{~kW} \mathrm{~m}^{-2}$. For $25 \mathrm{~kW} \mathrm{~m}^{-2}$, brushed fir and PUR foam and for 50 $\mathrm{kW} \mathrm{m}{ }^{-2}$ brushed fir showed very low $\mathrm{O}_{2}$ levels. The rest of tested samples show $\mathrm{O}_{2}$ levels higher than $14 \%$, therefore an anaerobic could not be considered. 


\section{Discussion and conclusions}

This work aims to analyse the oxygen level in the mixture layer produced in the combustion of the materials in cone calorimeter and elucidate if the hypothesis of zero-oxygen at that area when flame takes place can be generalised for every sort of material.

Results show oxygen concentration levels close to zero only for the PET under a flux of $25 \mathrm{~kW} \mathrm{~m}^{-2}$ and PET, Nylon and PUR foam under a flux of $50 \mathrm{~kW} \mathrm{~m}^{-2}$ and less than $5,5 \%$ for Brushed fir. The rest of the materials obtained oxygen levels quite different from zero. Char layer created during the cone test for Brushed fir, Nylon and PET played an important role as efficient heat barrier modifying the thermal behaviour of the materials by decreasing the mass loss rates.

A modification of the sample holder was built up by adding two additional tubes for sampling gases in the mixture layer, one in the center of the sample and another in the corner of the sample. Due to that modification we were able to measure the $\mathrm{O}_{2}$ and $\mathrm{CO}_{2}$ level during the test.

Theoretically that method was likely to modify plume flow or introduce air. Therefore, we ensured that the gas collected did not affect it is using such a low value of volumetric flow of $1.25 \times 10^{-5} \mathrm{~m}^{3} \mathrm{~s}^{-1}$ for the external gas analyser and, as a result, the amount of mass sampled was so small in comparison with the amount of gases released by the sample, as it was indicated in Table 5 (columns 5 and 6). In addition, in the worst conditions, the mass sampled represented only $44 \%$ (only for PET).

As opposed to the data obtained in the center of the sample, where the sampler tube is immersed in the gases from combustion, the data obtained in the corner tube should not be taken into account due to the possibility that they can be affected by the surrounding atmosphere and it can modify the values.

To stablish a comparison between cone calorimetric results and thermogravimetric test and analyse the influence of the oxygen in the cone calorimetric, materials were tested in TG with two different types of oxygen concentration: $21 \%$ and 0 $\%$. The reaction rates and percent of residue in the cone calorimetric tests were measured and compared with the results from thermogravimetric tests.

Previous works [14-20] discuss about that once the flame appears during the combustion, it consumes all oxygen and creates and inert atmosphere between the flame and material, i.e., material is decomposing in an inert atmosphere. Results in this work showed this frame for PET under a flux of $25 \mathrm{~kW} \mathrm{~m}^{-2}$ and PET, Nylon and PUR foam under a flux of $50 \mathrm{~kW} \mathrm{~m}{ }^{-2}$. For the rest of materials analysed in this work, $\mathrm{O}_{2}$ levels measured lead to suppose that materials decompose in oxidant conditions.

Among materials analysed in this work only brushed fir, and the Nylon (only at $50 \mathrm{~kW} \mathrm{~m}^{-2}$ ) could verify the zero oxygen hypotheses argued in [14-20]. Oxygen levels measured (in the center of the sample) in cone calorimeter are close to zero (less than 5,5\% for Brushed fir) and their residue after cone calorimeter test are similar to TG test in $\mathrm{N}_{2}$ atmosphere.

The correlation of char yield from cone and inert TG, for thicker char materials reported in the literature [14-19], obeys to the fact that char layer probably needs higher concentrations of oxygen to burn, showing high stability against oxidation like charcoal.

However, the rest of materials analysed, the char layer created during the test as efficient heat barrier reveals an important role during the test since the residual mass and mass loss rates do not agree with the thermogravimetric tests in any atmosphere. An analysis of minimum oxygen concentration needed to burn the char could help to elucidate better this question. There are several effects produced from the change of scale, and the importance of the thermal attack to the sample could modify the thermal behaviour of the material. Thermogravimetric test executed in this work created any layer of char as the cone calorimetric does.

Temperatures measured over surface of the sample indicates a huge heating rate before the ignition (up to $4 \mathrm{~K} \mathrm{~s}^{-1}$ ) while in TG tests heating is homogenous and have been performed at $10 \mathrm{~K} \mathrm{~min}^{-1}, 24$ times minor. According to this, we could expect higher reaction rates at cone than at TG ones. Nevertheless, higher reaction rates in TG tests were found, under both atmospheres, for brushed fir, Nylon and PET. In cone calorimeter test, material formed an effective layer of char which wraps where the exposed face of the material was protected. By the contrast, corrugated cardboard, PVC wall panelling and PUR foam) shown higher rates in cone when ignition takes place and the char layer created is not enough effective when 
materials are irradiated. Char layer that appears in some materials could play an important role during cone test, modifying the thermal behavior of the material.

Char layer plays a major role in the cone calorimeter for some materials. One of the conclusions in the work of Semmes, M et al. [23], where the influence of the oxygen concentration in the atmosphere in the kinetic parameters of the cardboard degradation was studied, was that the presence of semi-burnt particles on the surface of the sample, in large scale test, could have an important influence in the thermal decomposition.

To study the influence of the atmosphere in cone calorimetric should do it in a cone calorimetric scale. The fact of use thermogravimetric techniques that allow modify atmospheres and heating rates, and afterward extrapolate the data to cone calorimetric scale could not work for all materials. The recent work of Li, J. et al. [22] underlines that idea, where the samples (non-charring polymers) were tested under controlled atmosphere to analyse the heat transfer in pyrolysis with the purpose of validate anaerobic pyrolysis models based on thermogravimetric techniques.

\section{Acknowledgements}

Authors would like to thank to the Spanish Ministry of Economy and Competitiveness for the PYRODESIGN Project grant, Ref.: BIA2012-37890, financed jointly by FEDER funds.

\section{References}

1. Fang MX, Shen, DK, Li YX, Yu CJ, Luo, ZY, Cen KF. Kinetic study on pyrolysis and combustion of wood under different oxygen concentrations by using TG-FTIR analysis. Journal of analytical and applied pyrolysis. 2006;77(1):2227.

2. Ozawa T. Thermal analysis - review and prospect. Thermochimica Acta. 2000; 355(1):35-42.

3. ASTM-E1131-08. Standard test method for compositional analysis by thermogravimetry. ASTM International. 2014.

4. ASTM-E-1354-04a. Standard test method for heat and visible smoke release rates for materials and products using an oxygen consumption calorimeter. ASTM International. 2004.

5. Park WH, Yoon KB. Optimization of pyrolysis properties using TGA and Cone Calorimeter test. Journal of Thermal Science. 2013;22(2):168-173.

6. Lautenberger C, Rein G, Fernandez-Pello C. The application of a genetic algorithm to estimate material properties for fire modelling from bench-scale fire test data. Fire Safety Journal. 2006;41:204-214

7. Chaos M, Khan MM, Krishnamoorthy N, de Ris JL, Dorofeev SB. Evaluation of optimization schemes and determination of solid fuel properties for CFD fire models using bench-scale pyrolysis tests. Proceedings of the Combustion Institute. 2011;33:2599-2606

8. Webster RD. Pyrolysis model parameter optimization using a customized stochastic hill-climber algorithm and bench scale fire test data. Doctoral dissertation, 2009

9. Capote JA, Alvear D, Abreu O, Lazaro M, Puente E. Pyrolysis Characterization of a lineal low density polyethylene. Fire Safety Science. 2011;10:877-888

10. Stoliarov SI, Crowley S, Walters RN, Lyon RE. Prediction of the burning rates of charring polymers. Combustion and Flame. 2010;157(11):2024-2034.

11. Stoliarov SI, Crowley S, Walters RN, Lyon RE. Prediction of the burning rates of charring polymers. Combustion and Flame. 2010;157(11):2024-2034.

12. Stoliarov SI, Crowley S, Lyon RE, Linteris GT. Prediction of the burning rates of non-charring polymers. Combustion and Flame. 2009;156(5):1068-1083.

13. Linteris GT, Lyon RE, Stoliarov SI. Prediction of the gasification rate of thermoplastic polymers in fire-like environments. Fire Safety Journal. 2013;60:14-24.

14. Liu W, Varley RJ, Simon GP. Understanding the decomposition and fire performance processes in phosphorus and nanomodified high performance epoxy resins and composites. Polymer. 2007;48(8): 2345-2354.

15. Sacristán M, Hull TR, Stec AA, Ronda JC, Galià M, Cádiz V. Cone calorimetry studies of fire retardant soybean-oilbased copolymers containing silicon or boron: Comparison of additive and reactive approaches. Polymer Degradation and Stability. 2010;95(7):1269-1274.

16. Witkowski A, Stec AA, Hull TR. Thermal decomposition of polymeric materials (Chapter 7). Handbook of Fire Protection Engineering. Society of Fire Protection Engineers. 2016.

17. Lyon RE, Harper CA. Plastics and rubber. Handbook of building materials for fire protection. Chap 3:3.1-3.51. 2004, McGraw-Hill. 
18. Schartel B, Hull TR. Development of fire retarded materials-Interpretation of cone calorimeter data. Fire and materials. 2007; 31(5):327-354.

19. Fina A, Camino G. Ignition mechanisms in polymers and polymer nanocomposites. Polym. Adv. Technol. 2007;22: $1147-1155$.

20. Kim E, Dembsey N. Engineering guide for estimating material pyrolysis properties for fire modelling. Project Final Report, 382. 2012.

21. Lyon RE. Heat release kinetics. Fire and Materials. 2000;24:179-186.

22. Li J, Gong J, Stoliarov SI. Gasification experiments for pyrolysis model parameterization and validation. 2014, International Journal of Heat and Mass Transfer, 2014;77:738-744.

23. Semmes M, Liu X, McKinnon, M, Stoliarov SI, Witkowski A. A model for oxidative pyrolysis of corrugated cardboard. Fire safety science-draft proceedings of the eleventh international symposium. International Association For Fire Safety Science. 2014.

24. Brohez, S. Uncertainty analysis of heat release rate measurement from oxygen consumption calorimetry. Fire and Materials. 2005;29(6):383-394 